\title{
The role of polymerization cycle and post-pressing time on tooth movement in complete dentures
}

\section{Wagner Araujo de Negreiros ${ }^{(a)}$ Rafael Leonardo Xediek Consani(b) Marcus Aurelio Rabelo Lima Verde $^{(c)}$ \\ Antonio Materson da Silva(c) Lecio Pitombeira Pinto(d)}

(a) PhD, Professor, Department of Prosthodontics, School of Dentistry, Fortaleza University (UNIFOR), Fortaleza, CE, Brazil.

(b) $\mathrm{PhD}$, Professor, Department of Prosthodontics, Piracicaba Dental School, University of Campinas, Piracicaba, SP, Brazil.

(c) PhD, Professor, Department of Prosthodontics, School of Dentistry, Federal University of Ceará, Fortaleza, CE, Brazil.

(d) PhD, Researcher of the National PostDoctorate Program (PNPD-CNPa), Department of Restorative Dentistry, School of Dentistry, Federal University of Ceará, Fortaleza, CE, Brazil.

\section{Corresponding author:}

Wagner Araujo de Negreiros

Rua Prof. Dias da Rocha, 684, apto. 402,

Bairro Meireles

Fortaleza - CE - Brazil

CEP: 60170-310

E-mail:wagnerufc@yahoo.com.br

\begin{abstract}
This study analyzed the influence of polymerization cycle and post-pressing time on tooth movement in complete dentures. Forty maxillary complete dentures were fabricated and randomly assigned to 8 groups $(\mathrm{n}=5)$; the polymerization cycle (conventional long cycle in water bath, fast cycle in boiling water, and by microwave energy) and the postpressing time (immediate and 6 hours) were varied. Metal reference pins were placed on the incisal border of the central incisors (RI and LI), on the buccal cusp of the first premolars (RP and LP), and on the mesiobuccal cusp of the second molars (RM and LM). Two transverse and 2 anteroposterior distances were measured with a linear optical microscope (Olympus Optical Co., Tokyo, Japan) with an accuracy of .0005 mm, before and after processing the complete dentures. The data collected were submitted to analysis of variance (ANOVA) and the Tukey Test at a significance level of $5 \%$. When Clássico, a conventional heat-polymerizable acrylic resin, was polymerized by microwave energy, tooth movement was statistically significant for 2 distances, with the highest value being observed for the 6-hour post-pressing time. Onda-Cryl microwave acrylic resin processed by microwave energy presented the lowest tooth movement for 2 distances, considering the 6-hour post-pressing time. QC-20 acrylic resin presented no statistically significant change considering both post-pressing times in each distance evaluated. Tooth movement showed an asymmetric behavior, so the mastering of the processing method is essential to the precise execution of all laboratory steps, irrespective of the polymerization cycle and post-pressing time used.
\end{abstract}

Descriptors: Denture, complete; Tooth movement; Tooth, artificial; Acrylic resins. 


\section{Introduction}

Studies focusing on acrylic resin properties and laboratory steps for complete denture processing are common in the dental literature. ${ }^{1-3}$ The processing of acrylic resin complete dentures leads to an unavoidable thermal expansion on heating, contraction on cooling, and polymerization shrinkage. The inherent characteristics of this material produce an internal stress that is released during the deflasking stage, generating dimensional changes and denture base distortion. ${ }^{4}$ Some studies investigated other materials and techniques to overcome these problems, and microwave activation became the target of new studies. ${ }^{5-7}$ Microwave polymerization is highlighted because of its manipulation pattern of resins, its clinical use and dimensional accuracy. ${ }^{8,9}$ Other reports have shown that the bases polymerized by this method presented the same or a better fit on the cast than those that were conventionally polymerized. ${ }^{10,11}$

Another factor that may have a critical influence on dimensional changes is the delay in polymerizing the denture after the final pressing step. This procedure allows the resin mass to flow into all regions of the mold and thus relieve internal stress in the early stage after closure. ${ }^{12,13}$ This condition has not yet been analyzed in dentures processed by the microwave method.

Considering the complexity of complete denture processing, the aim of this study was to investigate the effect of polymerization cycle and post-pressing time on the displacement of teeth in maxillary complete dentures. The effect of polymerizing conventional heat-polymerizable acrylic resin by microwave activation was also evaluated.

\section{Material and Method}

Forty identical casts were poured from a silicone mold (Elite Double; Zhermack, Rovigo, Italy) of a metal master edentulous maxillary die without irregularities in the alveolar ridge walls. The casts were made of artificial type III dental stone (Herodent Soli-rock; Vigodent, RJ, Brazil) and the water/ powder ratio was 30:100.

A $2 \mathrm{~mm}$ thick wax plate (Epoxiglass; Epoxiglass Chemical Products, Diadema, SP, Brazil) measured with a caliper was used to make uniform denture bases. The height of the occlusion wax rim was $20 \mathrm{~mm}$ in the buccal sulcus of the cast and $10 \mathrm{~mm}$ in the second molar area. The maxillary stone cast was mounted in a Mondial 4000 semi-adjustable articulator (Bio-Art Dental Products, São Carlos, SP, Brazil) with the wax rim interocclusal relation according to the teeth of the mandibular metal cast teeth, using the following references: intercondylar distance in $\mathrm{M}$. Bennett angle at 15 degrees, and condylar guide at 30 degrees.

Left anterior teeth were arranged with the carved wax rim serving as a guide to the positions of the central and lateral incisors and canines. A similar procedure was used on the right side. The posterior teeth were arranged starting with the first premolar up to the second molar. A similar procedure was again used in the right arch. The arrangement of the teeth for the interocclusal relationship was anterior vertical overlap and posterior in Angle class I. After finishing the tooth arrangement of the first denture, a silicone matrix was made (Zetalabor, Zhermack, Rovigo, Italy) fitted to all buccal aspects of the denture, comprising the vestibular and incisal surfaces of anterior teeth and vestibular and occlusal surfaces of posterior teeth. The purpose of this matrix was to guide the standardized arrangement of the teeth in all the samples.

Metal reference pins (Cadena, Coats Textil Ltda., SP, Brazil) were fixed with instantaneous adhesive (Super Bonder; Loctite, São Paulo, SP, Brazil) at the incisal border of the central incisors, buccal cusp of the first premolars, and mesiobuccal cusp of the second molars to serve as reference to measure tooth movement (Figure 1). The following linear distances were considered: RP-LP (right premolar to left premolar), RM-LM (right molar to left molar), RI-RM (right incisor to right molar), and LILM (left incisor to left molar). The linear distances were measured with a STM microscope (Olympus Optical Co., Tokyo, Japan), with an accuracy of $0.0005 \mathrm{~mm}$.

The cast and wax pattern sets of groups I, II, VII, and VIII were flasked in the lower part of a glass fiber flask (BMF1, Clássico Dental Products, São Paulo, SP, Brazil) for microwave polymeriza- 


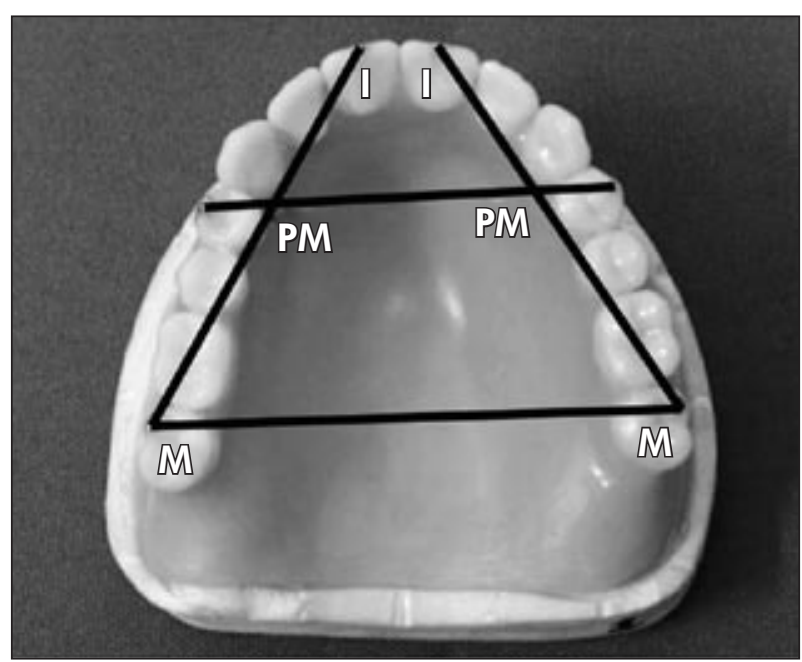

Figure 1 - Complete denture polymerized, metal reference pins, and distances evaluated.

tion, and the sets of groups III, IV, V, and VI were flasked in the lower part of a traditional brass flask (Safrany; J Safrany Dental Metallurgy, São Paulo, SP, Brazil) with type II dental stone (Pasom; Dental Products, SP, Brazil). Petroleum jelly (Labsynth; Labsynth Chemical Products, Diadema, SP, Brazil) was used as a separating medium between the plaster in the lower part of the flask and the type III dental stone used in the upper portion. After 1 hour, the flasks were placed in boiling water to soften the baseplate wax. The flasks were separated, the wax removed, and the stone was cleaned with boiling water and liquid detergent (Ype; Chemical Amparo, Amparo, SP, Brazil). Two coats of sodium alginate (Isolak; Clássico Dental Products) were used as a mold separator.

The acrylic resins, processing methods, and respective manufacturers evaluated in this study are shown in Table 1.

The resins were proportioned and prepared in accordance with the manufacturer's directions and each sample was packed in accordance with the group assignments: Group I and II (CLA-MICRO): Clássico conventional heat-polymerizable acrylic resin polymerized for 3 minutes at 35\%, 4 minutes at $0 \%$, and 3 minutes at $65 \%$ power of the $900 \mathrm{~W}$ microwave oven (Continental Domestic Products, Manaus, AM, Brazil); Group III and IV (CLA-WATER): Clássico conventional heat-polymerizable acrylic resin polymerized in a water bath at $74^{\circ} \mathrm{C}$ for 9 hours in a thermo-curing unit (Thermotron Dental Products, Piracicaba, SP, Brazil); Group V and VI (QC-20): QC-20 fast heat-polymerizable acrylic resin processed in boiling water for 20 minutes; Group VII and VIII (ONDA-CRYL): Onda-Cryl microwave acrylic resin processed under the same conditions as Group 1. Groups I, III, V, and VII were polymerized immediately after the pressing stage, while for Groups II, IV, VI, and VIII there was a 6 hour delay before polymerization.

After polymerization, the flasks of Groups I, II, VII, and VIII were removed from the microwave oven, and those of Groups III, IV, V, and VI were slowly cooled in the water bath, removed from the thermo-curing unit, and bench stored for 3 hours. After cooling, the dentures were deflasked, polished, and the transverse and anteroposterior distances were measured again. The data collected were submitted to analysis of variance (ANOVA) and the Tukey Test at a significance level of 5\%.

\section{Results}

Considering the 6-hour post-pressing time, and the distances RP-LP and RI-RM, group VIII (ONDA-CRYL) presented statistically $(\mathrm{p}<0.05)$ less tooth movement than all other groups (Tables 2 and 4). Within the CLA-MICRO groups, tooth move-

\begin{tabular}{|c|c|c|c|}
\hline \multirow{4}{*}{$\begin{array}{l}\text { Table } 1 \text { - Acrylic resins, } \\
\text { processing methods, and } \\
\text { respective manufacturers. }\end{array}$} & Resin trademark & Processing method & Manufacturer \\
\hline & $\begin{array}{l}\text { Clássico } \\
\text { (lot 90017.0) }\end{array}$ & $\begin{array}{l}\text { Conventional long cycle in } \\
\text { water bath }\end{array}$ & $\begin{array}{l}\text { Clássico Dental Products, São Paulo, } \\
\text { SP, Brazil }\end{array}$ \\
\hline & $\begin{array}{l}\text { Onda-Cryl } \\
\text { (lot 7150.50) }\end{array}$ & Microwave energy & $\begin{array}{l}\text { Clássico Dental Products, São Paulo, } \\
\text { SP, Brazil }\end{array}$ \\
\hline & $\begin{array}{l}\text { QC-20 } \\
(\text { lot } 580311-580313)\end{array}$ & Fast cycle in boiling water & $\begin{array}{l}\text { Dentsply, Dental Products, Rio de } \\
\text { Janeiro, RJ, Brazil }\end{array}$ \\
\hline
\end{tabular}


Table 2 - Means and standard deviations $(\mathrm{mm})$ of the linear distance RP-LP according to polymerization cycle and post-pressing time.

\begin{tabular}{c|c|c|c|c}
\hline \multirow{2}{*}{ Post-pressing time } & \multicolumn{4}{|c}{ Polymerization cycle } \\
\cline { 2 - 5 } & CLA-MICRO & CLA-WATER & QC-20 & ONDA-CRYL \\
\hline Immediate & $\mathrm{I}-39.02(0.46) \mathrm{Aa}$ & $\mathrm{III}-38.31(0.83) \mathrm{Ab}$ & $\mathrm{V}-38.64(0.55) \mathrm{Aa}$ & $\mathrm{VII}-38.39(0.76) \mathrm{Aa}$ \\
\hline 6-hour & $\mathrm{II}-39.07(0.59) \mathrm{Aa}$ & $\mathrm{IV}-39.04(0.66) \mathrm{Aa}$ & $\mathrm{VI}-38.58(0.63) \mathrm{ABa}$ & $\mathrm{VIII}-37.96(0.75) \mathrm{Ba}$ \\
\hline
\end{tabular}

Means followed by the same capital letter in each row and the same lowercase letter in each column were not significantly different $(5 \%)$.

Table 3 - Means and standard deviations $(\mathrm{mm})$ of the linear distance RM-LM according to polymerization cycle and post-pressing time.

\begin{tabular}{c|c|c|c|c}
\hline \multirow{2}{*}{ Post-pressing Time } & \multicolumn{4}{|c}{ Polymerization cycle } \\
\cline { 2 - 5 } & CLA-MICRO & CLA-WATER & QC-20 & ONDA-CRYL \\
\hline Immediate & $\mathrm{I}-50.81(0.86) \mathrm{Ab}$ & $\mathrm{III}-51.35(0.75) \mathrm{Aa}$ & $\mathrm{V}-50.90(0.38) \mathrm{Aa}$ & $\mathrm{VII}-51.23(0.71) \mathrm{Aa}$ \\
\hline 6-hour & $\mathrm{II}-51.58(0.44) \mathrm{Aa}$ & $\mathrm{IV}-51.54(0.83) \mathrm{Aa}$ & $\mathrm{VI}-50.96(0.57) \mathrm{Aa}$ & $\mathrm{VIII}-50.88(0.39) \mathrm{Aa}$ \\
\hline
\end{tabular}

Means followed by the same capital letter in each row and the same lowercase letter in each column were not significantly different $(5 \%)$.

Table 4 - Means and standard deviations $(\mathrm{mm})$ of the linear distance RI-RM according to polymerization cycle and post-pressing time.

\begin{tabular}{c|c|c|c|c}
\hline \multirow{2}{*}{ Post-pressing Time } & \multicolumn{4}{|c}{ Polymerization cycle } \\
\cline { 2 - 5 } & CLA-MICRO & CLA-WATER & QC-20 & ONDA-CRYL \\
\hline Immediate & $\mathrm{I}-41.46(0.66) \mathrm{ABb}$ & $\mathrm{III}-41.62(0.38) \mathrm{Aa}$ & $\mathrm{V}-41.13(0.26) \mathrm{Ba}$ & $\mathrm{VII}-41.76(0.27) \mathrm{Aa}$ \\
\hline 6-hour & $\mathrm{II}-41.96(0.32) \mathrm{Aa}$ & $\mathrm{IV}-41.75(0.48) \mathrm{Aa}$ & $\mathrm{VI}-41.11(0.19) \mathrm{Ba}$ & $\mathrm{VIII}-40.92(0.33) \mathrm{Bb}$ \\
\hline
\end{tabular}

Means followed by the same capital letter in each row and the same lowercase letter in each column were not significantly different $(5 \%)$.

Table 5 - Means and standard deviations $(\mathrm{mm})$ of the linear distance LI-LM according to polymerization cycle and post-pressing time.

\begin{tabular}{c|c|c|c|c}
\hline \multirow{2}{*}{ Post-pressing Time } & \multicolumn{4}{|c}{ Polymerization cycle } \\
\cline { 2 - 5 } & CLA-MICRO & CLA-WATER & QC-20 & ONDACRYL \\
\hline Immediate & $\mathrm{I}-40.30(0.84) \mathrm{Ab}$ & $\mathrm{III}-40.62(0.50) \mathrm{Aa}$ & $\mathrm{V}-40.56(0.15) \mathrm{Aa}$ & $\mathrm{VII}-40.56(0.39) \mathrm{Aa}$ \\
\hline 6-hour & $\mathrm{II}-40.84(0.26) \mathrm{Aa}$ & $\mathrm{IV}-40.65(0.52) \mathrm{Aa}$ & $\mathrm{VI}-40.64(0.42) \mathrm{Aa}$ & $\mathrm{VIII}-40.72(0.61) \mathrm{Aa}$ \\
\hline
\end{tabular}

Means followed by the same capital letter in each row and the same lowercase letter in each column were not significantly different $(5 \%)$.

ment was greater for the distances RM-LM and LILM, with statistical significance $(\mathrm{p}<0.05)$ for Group II (Tables 3 and 5).

\section{Discussion}

The pursuit of an efficient, practical and fast laboratory technique to make esthetically satisfactory complete dentures without undergoing great dimensional changes remains a challenge. As suggested by Lorton, Phillips ${ }^{14}$ (1979), the dimensional changes that occur in acrylic resin dentures are complex, and many processing variables interact with one another simultaneously.

In the present study, it was difficult to choose the best processing technique among the eight that were analyzed. A classical study reported that the long cycle processed in a water bath is recommendable, as less dimensional change occurred in the base. ${ }^{15}$ However, this method behaved in a similar manner to the other method, considering the mag- 
nitude of tooth movement in most of the distances evaluated. In the fast cycle in boiling water, incomplete polymerization of the resin may occur because of the rapid heating with temperature peaks, generating a great deal of exothermic heat. ${ }^{16}$ In the present study, long and fast cycles in water bath were alike as regards dimensional stability, and this phenomenon also characterizes the complexity of all the factors that interact during complete denture processing. ${ }^{14}$ The thermal and polymerization shrinkage obtained in the fast cycle were probably insignificant, or minimized by the action of other variables as, for example, expansion of the stone or water sorption.

The conventional water bath cycle is characterized by producing extensive molecular interactions, condensing the molecules to a greater extent, and shrinking the final structure after polymerization. On the other hand, the microwave activation provides faster and more intense energy, with interactions capable of linking monomer and polymer and polymerizing the resin. The bases polymerized by this method presented the same or a better fit on the cast than those conventionally polymerized. ${ }^{10,11}$ Although these reports argue in favor of the microwave processing method, its superiority was not verified in this study for most of the distances evaluated. Only for 2 distances, group VIII (ONDA-CRYL) presented statistically $(\mathrm{p}<0.05)$ less tooth movement than all other groups (Tables 2 and 4).

The use of conventional heat-polymerizable acrylic resins and polymerizing them by the microwave method showed no great damage in this study; however, a previous study reported the occurrence of more changes, such as porosities due to the application of the conventional material. ${ }^{17}$ The microwave energy generated by the "magnetron" of the microwave oven may produce a dielectric heating in which the energy is immediately and uniformly absorbed by the resin. This method may reduce the time of heat transference from the water to the flask, from the flask to the cast, and from the cast to the resin, as occurs in the conventional polymerization cycle. ${ }^{18}$ The described phenomenon probably occurred for all resin types in this study, irrespective of their components, causing similar dimensional changes in tooth position. This finding is in agreement with the Braun et al. ${ }^{5}$ (2000) study, which concluded that the conventional heat-polymerizable acrylic resins showed similar dimensional changes to those of resins specially designed for polymerization by microwave activation.

The 6-hour post-pressing time was chosen as a variable because it seems to be the minimum and effective period for demonstrating resin relaxation, and, at the same time, a possible technical condition to be applied in the laboratory routine. One reason for allowing the flask to stand for some hours before polymerizing would be to reduce the amount of residual monomer present in the resin dough. ${ }^{12}$ In this study, the 6-hour post-pressing time had no advantage in reducing the magnitude of tooth movement in most of the distances evaluated, which was different from the findings of the Consani et al. ${ }^{13}$ (2004) study in relation to the basis fit. This procedure had no significant effect on allowing the resin mass to flow into all regions of the mold, relieve internal stress, and generate less dimensional change.

It is obvious that, irrespective of the polymerization cycle and post-pressing time used, the complexity of the stresses in the denture also involves other important factors that generate displacement of the artificial teeth. The many findings in the literature to the effect that no differences in tooth movement were shown among the tested groups, ${ }^{19,20}$ as opposed to other studies that showed that there was a best method, ${ }^{9,21}$ maintain this subject open for further investigation.

\section{Conclusion}

According to the methodology of this study, the performance of microwave polymerization was similar to that of the conventional cycles in water bath, and post-pressing time had no relevant effect on tooth movement. This study observed an asymmetric linear tooth movement among the processing groups, without evidence to determine the best processing group. Therefore, whatever the technique used for processing, it is essential that it be meticulously controlled. 


\section{References}

1. John J, Gangadhar SA, Shah I. Flexural strength of heatpolymerized polymethyl methacrylate denture resin reinforced with glass, aramid, or nylon fibers. J Prosthet Dent. 2001;86(4):424-7.

2. Meloto CB, Silva-Concílio LR, Machado C, Ribeiro MC, Joia FA, Rizzatti-Barbosa CM. Water Sorption of Heat-Polymerized Acrylic Resins Processed in Mono and Bimaxillary Flasks. Braz Dent J. 2006;17(2):122-5.

3. Barbosa DB, Compagnoni MA, Leles CR. Changes in occlusal vertical dimension in microwave processing of complete dentures. Braz Dent J. 2002;13(3):197-200.

4. Botega DM, Machado TS, Mello JAN, Rodrigues-Garcia RCM, Cury AADB. Polymerization time for a microwavecured acrylic resin with multiple flasks. Braz Oral Res. 2004;18(1):23-8.

5. Braun KO, Rodrigues Garcia RCM, Rizzatti-Barbosa CM, Del Bel Cury AA. Linear dimensional change of denture base resins cured by microwave activation. Braz Oral Res. 2000;14(3):278-82.

6. Pavan S, Arioli Filho JN, Dos Santos PH, Mollo F de A Jr. Effect of microwave treatments on dimensional accuracy of maxillary acrylic resin denture base. Braz Dent J. 2005;16(2):11923.

7. Pero AC, Barbosa DB, Marra J, Ruvolo-Filho AC, Compagnoni MA. Influence of Microwave Polymerization Method and Thickness on Porosity of Acrylic Resin. J Prosthodont. 2007;17(2):125-9.

8. Blagojevic V, Murphy VM. Microwave polymerization of denture base materials. A comparative study. J Oral Rehabil. 1999;26(10):804-8.

9. Keenan PJL, Radford DR, Clark RKF. Dimensional change in complete dentures fabricated by injection molding and $\mathrm{mi-}$ crowave processing. J Prosthet Dent. 2003;89(1):37-44.
10. Al-Hanbali E, Kalleway JP, Howlett JA. Acrylic denture distortion following double processing with microwave or heat. J Dent. 1991;19(3):176-80.

11. Levin B, Sanders JL, Reitz PV. The use of microwave energy for processing acrylic resins. J Prosthet Dent. 1989;61(3):3813.

12. Peyton FA. Packing and pressing denture base resins. J Am Dent Assoc. 1950;40(5):520-8.

13. Consani RLX, Domitti SS, Mesquita MF, Consani S. Effect of packing types on the dimensional accuracy of denture base resin cured by the conventional cycle in relation to post-pressing times. Braz Dent J. 2004;15(1):63-7.

14. Lorton L, Phillips RW. Heat-released stress in acrylic dentures. J Prosthet Dent. 1979;42(1):23-6.

15. Stanford JW, Paffenbarger GC. Processing denture base resins: heat-cure type. J Am Dent Assoc. 1956;53(1):72-3.

16. Yau WFE, Cheng YY, Clark RKF, Chow TW. Pressure and temperature changes in heat-cured acrylic resin during processing. Dent Mater. 2002;18(8):622-9.

17. Yannikakis S, Zissis A, Polyzois G, Andreopoulos A. Evaluation of porosity in microwave-processed acrylic resin using a photographic method. J Prosthet Dent. 2002;87(6):613-9.

18. Walace PW, Graser GN, Myers ML, Proskin HM. Dimensional accuracy of denture resin cured by microwave energy. J Prosthet Dent. 1991;66(3):403-8.

19. Garfunkel E. Evaluation of dimensional changes in complete dentures processed by injection-pressing and the pack-andpress technique. J Prosthet Dent. 1983;50(6):757-61.

20. Consani RLX, Domitti SS, Mesquita MF, Consani S. Influence of flask closure and flask cooling methods on tooth movement in maxillary dentures. J Prosthodont. 2006;15(4):229-34.

21. Polyzois GL, Karkazis HC, Zissis AJ, Demetriou PP. Dimensional stability of denture processed in boilable acrylic resins: a comparative study. J Prosthet Dent. 1987;57(5):639-47. 